\title{
Change in the concentration of urolithiasis markers depending on the degree of activity of stone formation in patients with recurrent stone disease
}

\begin{abstract}
The goal of the research: To study the change in the concentration of bikunin, osteopontin and nephrocalcin, depending on the change of the activity of urolithiasis in patients with recurrent stone disease.

Materials and methods: The study involved 152 patients with recurrent formation of calcium oxalate stones. All patients were divided into 2 groups: 78 patients who received complex preventive treatment (water load, Blemaren, thiazide diuretics, calcium inwards), and 74 patients who did not receive treatment. The concentration of bikunin, osteopontin and nephrocalcin in urine was measured by ELISA. We also measured the intensity of stone formation by means of $\mathrm{x}$-ray spectral microanalysis of the urine samples. The follow-up period was 6 months, the examination was carried out 3 times - at the beginning of the study, on 3 months and in the end of the observation period after 6 months.
\end{abstract}

Results: After 6 months of observation, the bikunin concentration was significantly higher in the group of patients who did not receive treatment compared to patients who received preventive therapy $(6,12 \pm 0,57 \mathrm{mg} / \mathrm{ml}$ vs $3,28 \pm 0,86 \mathrm{mg} / \mathrm{ml}$, respectively). The concentration of osteopontin in the group of patients who did not receive treatment was significantly lower $(2,3 \pm 0,39 \mathrm{mg} / \mathrm{ml}$ vs $3,4 \pm 0,36 \mathrm{mg} / \mathrm{ml})$. The concentration of nephrocalcin during the observation period did not change significantly. The presence of hypercalciuria does not lead to significant changes in the concentration of stone formation inhibitors.

Discussion: An increase in bikunin concentration in patients who did not receive treatment during the observation period is associated with an increase in the expression of this stone formation inhibitor due to an increase in the activity of urolithiasis. Reduction of the concentration of osteopontin in patients with high activity of urolithiasis is a consequence of the fact that osteopontin is a constituent component of calcium oxalate stones

Conclusion: The measurement of the concentration of bikunin and osteopontin in urine, as potential markers, can be used in the early diagnosis of urolithiasis in order to determine the probability of a possible relapse in patients with calcium oxalate urolithiasis.
Volume 6 Issue 2 - 2018

\section{Kamalov A, ${ }^{1,2}$ Nizov A, ${ }^{1,2}$ Ohobotov D'}

'Director-academician, Moscow Research and Education Center of the Lomonosov Moscow State University, Russia

${ }^{2}$ Rector-academician, Urology and Andrology Department, Lomonosov Moscow State University, Russia

Correspondence: Dr. Nizov Aleksei, Urologist in Moscow Research and Education Center of the Lomonosov Moscow State University, PhD student of the Faculty of Fundamental Medicine of the Lomonosov Moscow State University, Russia, Tel 89687587565,Email nizovale@gmail.com.

Received: February 21, 2018| Published: March 20, 2018

\section{Introduction}

Significant progress in the field of endourology allows to remove the vast majority of stones in the urinary tract. ${ }^{1}$ However, removal of stones does not guarantee that in the future there will be no recurrence of urolithiasis, since surgery is aimed at eliminating the consequences of this disease. ${ }^{2}$ In most cases, patients after discharge received incomplete recommendations and after a few months or years come to the emergency department with relapse. ${ }^{3}$ Treatment of urolithiasis should not be symptomatic. Prevention of urolithiasis and monitoring of the disease activity is the chief task for urologist, who participates in treatment of patients with recurrent urolithiasis. ${ }^{4}$

\section{Materials and methods}

The basis of the clinical part of the study based on the results of examination and treatment of patients with urolithiasis in Moscow Research and Education Center of the Lomonosov Moscow State University. A total of 834 cases were analyzed in the period from 2015 to 2018 . We distinguish among 834 patients 260 with recurrent urolithiasis. Further patients underwent a comprehensive urological examination, including a stone spectroscopy.

The inclusion criteria were:

1. Men and women over the age of 18

2. Relapsing course of kidney stones (more than 1 relapse history). 
By relapse we mean either the clinical manifestation of urolithiasis (renal colic) or the discovery of a new stones using ultrasound or CT scan

\section{Verified calcium oxalate urolithiasis}

4. No secondary forms of urolithiasis (malabsorption syndrome, primary hyperparathyroidism)

\section{The patient is able to understand and give informed consent}

15 patients were excluded from 260 patients during the examination due to insufficient clinical and laboratory data. Only 152 patients with calcium oxalate urolithiasis were selected from 240 patients in this study taking into account the inclusion criteria. All patients with calcium oxalate urolithiasis were divided into two groups. Patients from the first group (78 patients) were received treatment for 6 months. The 2nd group included 74 patients who were not prescribed therapy. The follow-up period was 6 months; the control examination was conducted every 3 months.

Treatment prescribed to patients from the first group included the following components: calcium $1200 \mathrm{mg}$ inward (Calcium-D3 Nycomed), citrate mixtures (Blemaren) with maintenance of optimal $\mathrm{pH}$ of urine 6.2-6.8, water load (2 liters of liquid per day), oxalate diet (recommended products: apples, pears, plums, dogwood, grapes, decoctions from fruits; exclude: sorrel, potatoes, beets, beet, rhubarb, beans, rhubarb figs, parsley, onion, black currant, blueberry, gooseberry, cocoa, coffee, chocolate), hydrochlorothiazide $25 \mathrm{mg}$ per day for the entire period of observation..$^{2,5-7}$

As part of the study all patients on each visit underwent a comprehensive urological examination, which also included x-ray spectral microanalysis, measurement of the concentration of markers (bikunin, nephrocalcin, osteopontin) and determination of the daily concentration of calcium ions and oxalates. X-ray spectral microanalysis allows determining the degree of activity of the crystals growth process. Pathological structural changes in urine, during its transition from liquid to solid state, reveal the phenomenon of salt crystals formation. Also some patients, who had not performed a spectroscopy of the stone before going to the clinic, were analyzed for the composition of the stone.

Calcium concentrations greater than $4 \mathrm{mg} / \mathrm{kg} /$ day were defined as hypercalciuria, and calcium oxalate concentration greater than $40 \mathrm{mg}$ / day was defined as hyperoxaluria. ${ }^{8}$

\section{Results and discussion}

We measured the concentration of potential markers of urolithiasis (bikunin, nephrocalcin, osteopontin) at different stages of observation. The activity of stone formation as mentioned above was measured by $\mathrm{x}$-ray spectral microanalysis (from 0 to 3 , where 3 -the highest degree of activity of stone formation). Results of changes in the concentration of crystallization inhibitors and stone disease activity are seen below in Table 1.

The concentration of bikunin decreased significantly in 6 months after the end of treatment (from $5.97 \pm 0.94 \mathrm{mg} / \mathrm{ml}$ to $3.28 \pm 0.86$ ). The concentration of osteopontin increased significantly (from $2.2 \pm 0.32 \mathrm{mg} / \mathrm{ml}$ to $3.4 \pm 0.36 \mathrm{mg} / \mathrm{ml}$ ). There were no significant changes in the concentration of nephrocalcin during the entire observation period. Such a change in the concentration of bikunin can be explained by the negative feedback. The expression of bikunin increases with high stone formation activity. For osteopontin, the increase in the concentration of this inhibitor in stone formers is due to the fact that osteopontin is one of the main components of the calcium-oxalate stones matrix. The concentration of the free fraction of osteopontin will increase with a decrease in the number of nucleation points and crystallization. The concentration of nephrocalcin during the whole period of observation did not change significantly. The results of the $\mathrm{x}$-ray spectral microanalysis show the effectiveness of the prescribed therapy. Almost all patients of the study group (69 patients out of 78) had the low activity of stone formation.

Table I Changes in the concentration of bikunin, nephrocalcin, osteopontin in the group of patients who were prescribed treatment $(n=78)$

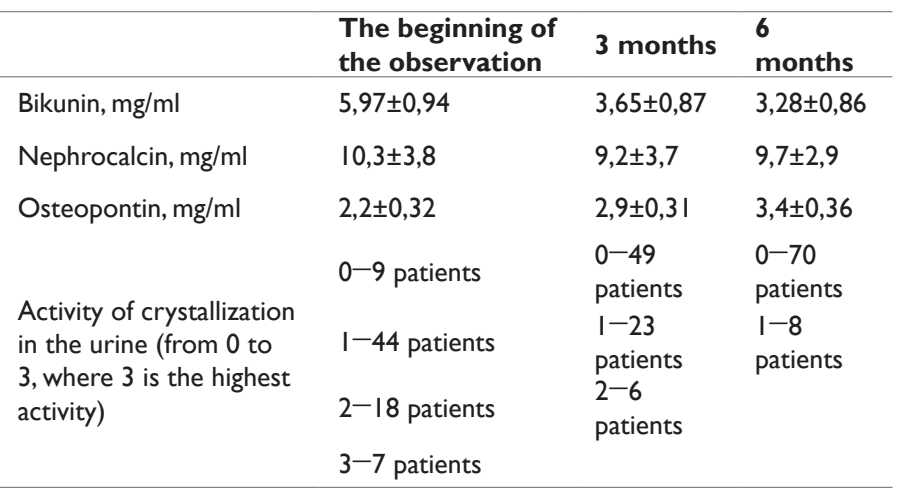

0, No activity of stone formation.

I, Low degree of activity of stone formation.

2 , The average degree of activity of stone formation.

3 , High degree of activity of stone formation.

Changes in the concentration of bikunin, nephrocalcin, osteopontin in the group of patients who have not been prescribed treatment are presented below in Table 2 .

Table 2The change in the concentration of bikunin, nephrocalcin, osteopontin in the group of patients with no treatment $(n=74)$

\begin{tabular}{|c|c|c|c|}
\hline & $\begin{array}{l}\text { The beginning } \\
\text { of the } \\
\text { observation }\end{array}$ & 3 months & $\begin{array}{l}6 \\
\text { months }\end{array}$ \\
\hline Bikunin, mg/ml & $5,86 \pm 0,85$ & $6,44 \pm 0,95$ & $6,12 \pm 0,57$ \\
\hline Nephrocalcin, mg/ml & $1 \mathrm{I}, 3 \pm 2,8$ & $9,2 \pm 2,9$ & $12,3 \pm 3,7$ \\
\hline Osteopontin, mg/ml & $2,3 \pm 0,32$ & $2,4 \pm 0,35$ & $2,3 \pm 0,39$ \\
\hline \multirow{3}{*}{$\begin{array}{l}\text { Activity of crystallization } \\
\text { in the urine (from } 0 \text { to } \\
3 \text {, where } 3 \text { is the highest } \\
\text { activity) }\end{array}$} & $0-19$ patients & $\begin{array}{l}0-18 \\
\text { patients }\end{array}$ & $\begin{array}{l}0-18 \\
\text { patients }\end{array}$ \\
\hline & $\mathrm{I}-35$ patients & $\begin{array}{l}\mathrm{I}-35 \\
\text { patients }\end{array}$ & $\begin{array}{l}\mathrm{I}-36 \\
\text { patients }\end{array}$ \\
\hline & 2-20 patients & 2-patients & $\begin{array}{l}2-20 \\
\text { patients }\end{array}$ \\
\hline
\end{tabular}

0 , No activity of stone formation

I, Low degree of activity of stone formation

2 , The average degree of activity of stone formation

3 , High degree of activity of stone formation

During the observation period there were no significant changes in 
the concentration of bikunin, nephrocalcin, osteopontin. The activity of urolithiasis also did not change in patients in the observation process. The absence of changes in the concentration of stone formation markers in patients who have not received treatment shows the effect of preventive therapy on the activity of stone formation.

Some patients during standard urological investigation were diagnosed with hypercalciuria or hyperoxaluria. At the beginning of follow-up, the number of such patients in group $1(\mathrm{n}=78)$, in which patients received conservative treatment, amounted to 29 people (19 patients with hyperoxaluria and 10 patients with hypercalciuria). All the other patients in our study in both groups had normal concentration of the calcium and oxalates.

Below are the values of marker concentrations during the entire follow-up period in patients from the $1^{\text {st }}$ group, in which treatment was prescribed, depending on the presence of hypercalciuria or hyperoxaluria.

Our findings show that patients with hypercalciuria and oxaluria significantly higher concentration bikunin and lower concentration osteopontin, which suggests a more intensive process of crystallization. The concentration of nephrocalcin has not changed significantly. We also compared the values of markers of stone disease after a course of conservative therapy. The results are presented in Table 3.

As can be seen from the data presented in Table $3 \&$ Table 4 in patients with hypercalciuria after 6 months from the start of treatment, there is a slight decrease in the concentration of bikunin $(8,23 \pm 1,54 \mathrm{mg} / \mathrm{ml}$ vs $6,23 \pm 1,47 \mathrm{mg} / \mathrm{ml}, \mathrm{p}>0.05)$ and an increase in the concentration of osteopontin $(2,0 \pm 0,032 \mathrm{mg} / \mathrm{ml}$ vs $2,1 \pm 0,42 \mathrm{mg} / \mathrm{ml}$, $\mathrm{p}>0.05$ ), but these changes are not reliable. The change in the activity of stone formation in patients with hypercalciuria also occurred less intensively than in other patients.

Table 3 The value of the concentration of stone inhibitors in patients of the first group $(n=78)$ before treatment, depending on the presence of hypercalciuria or hyperoxaluria

\begin{tabular}{|c|c|c|c|}
\hline & $\begin{array}{l}\text { Hypercalciuria } \\
(n=10)\end{array}$ & $\begin{array}{l}\text { Hyperoxaluria } \\
(n=19)\end{array}$ & $\begin{array}{l}\text { Normal concentration of } \\
\text { oxalate and calcium }(n=49)\end{array}$ \\
\hline bikunin, mg/ml & $8,23 \pm I, 54$ & $7,98 \pm 0,82$ & $5,25 \pm 0,45$ \\
\hline nephrocalcin, mg/ml & $12,6 \pm 4,3$ & $\mathrm{II}, 3 \pm 3, \mathrm{I}$ & $\mid 2, I \pm 3,2$ \\
\hline \multirow[t]{2}{*}{ osteopontin, mg/ml } & $2,0 \pm 0,32$ & $2, I \pm 0,36$ & $2,4 \pm 0,33$ \\
\hline & $0-3$ patients & $\mathrm{I}-10$ patients & 0-9 patients \\
\hline \multirow{3}{*}{$\begin{array}{l}\text { Activity of crystallization in the urine } \\
\text { (from } 0 \text { to } 3 \text {, where } 3 \text { is the highest } \\
\text { activity) }\end{array}$} & I-7 patients & 2-9 patients & $|-3|$ patients \\
\hline & & & $2-2$ patients \\
\hline & & & 3-7 patients \\
\hline
\end{tabular}

0 , No activity of stone formation

I, Low degree of activity of stone formation

2, The average degree of activity of stone formation

3 , High degree of activity of stone formation

Table 4 The value of the concentration of stone inhibitors in patients of the first group $(n=78)$ after treatment (after 6 months), depending on the presence of Hypercalciur or hyperoxaluria

\begin{tabular}{|c|c|c|c|}
\hline & Hypercalciuria $(n=10)$ & $\begin{array}{l}\text { Hyperoxaluria } \\
(n=19)\end{array}$ & $\begin{array}{l}\text { Normal concentration of } \\
\text { oxalate and calcium }(n=49)\end{array}$ \\
\hline bikunin, $\mathrm{mg} / \mathrm{ml}$ & $6,23 \pm 1,47$ & $6,12 \pm 0,76$ & $3,96 \pm 0,48$ \\
\hline nephrocalcin, $\mathrm{mg} / \mathrm{ml}$ & $11,3 \pm 3,5$ & $10,8 \pm 3,6$ & $\mid \mathrm{I}, 7 \pm 4, \mathrm{I}$ \\
\hline osteopontin, $\mathrm{mg} / \mathrm{ml}$ & $2, I \pm 0,42$ & $2,9 \pm 0,35$ & $3,6 \pm 0,37$ \\
\hline $\begin{array}{l}\text { Activity of crystallization in the } \\
\text { urine (from } 0 \text { to } 3 \text {, where } 3 \text { is the } \\
\text { highest activity) }\end{array}$ & $\begin{array}{l}0-3 \text { patients } \\
\text { I-7 patients }\end{array}$ & $0-18$ patients & 0-49 patients \\
\hline
\end{tabular}

0 , No activity of stone formation

I, Low degree of activity of stone formation

2, The average degree of activity of stone formation

3 , High degree of activity of stone formation

In patients with hyperoxaluria there is a significant decrease in the concentration of bikunin $(7.98 \pm 0.82 \mathrm{mg} / \mathrm{ml}$ vs $6.12 \pm 0.76 \mathrm{mg}$ / $\mathrm{ml}, \mathrm{p}<0.05)$ and an increase in the concentration of osteopontin $(2.1 \pm 0.36 \mathrm{mg} / \mathrm{ml}$ vs $2.9 \pm 0.35 \mathrm{mg} / \mathrm{ml}, \mathrm{p}<0.05)$. The reduction of the concentration bikunin and increase concentration osteopontin in patients without increased concentration of calcium and oxalates in

the urine after the treatment are accurate. There were no significant changes in the concentration of measured substances in the untreated group during the observation period. The change in the concentration of stone formation inhibitors in patients with hyperoxaluria is more pronounced than in patients with hypercalciuria, which is most likely due to different pathogenesis of stone formation. Such differences 
dictate the need for genetic research, which is one of the goals of this work.

\section{Conclusion}

The treatment of patients with calcium oxalate urolithiasis leads to a significant reduction in the activity of crystallization activity. The maximum effect recorded after 6 months of preventive therapy. Concentrations of crystallization inhibitors (bikunin, nephrocalcin, osteopontin) vary throughout the observation period, depending on changes in the activity of urolithiasis. An increase in the concentration of bikunin above $5 \mathrm{mg} / \mathrm{ml}$ and a decrease in the concentration of osteopontin below $2.2 \mathrm{mg} / \mathrm{ml}$ can indicate the increase likelihood of kidney stone disease recurrence.

\section{Acknowledgements}

None.

\section{Conflict of interest}

Authors declare there is no conflict of interest in publishing the article.

\section{References}

1. Alyaev YG, Amosov AV, Saenko VS. Metaphylactic urolithiasis. Moscow, Russia, EKSMO; 2007. 350 p.
2. Barbera M, Sirgiotis A, Paola Q. The importance of citrates in treatment and prophylaxis of calcium oxalate urinary stones. Arch Ital Urol Androl. 2016;88(4):343-344.

3. Coe FL, Worcester EM, Andrew P Evan. Idiopathic hypercalciuria and formation of calcium renal stones. Nat Rev Nephrol. 2016;2(9):519-533.

4. Wolfgram DF, Gundu V, Astor BC, et al. Hydrochlorothiazide compared to chlorthalidone in reduction of urinary calcium in patients with kidney stones. Urolithiasis. 2013;41(4):315-322.

5. Urology by Donald Smith. E \& J Flue Makanin's. editors, Moscow, PRACTICE; 2005. 819 p.

6. Zharikov AY, Motin YG, Zverev YF, et al. Expression of renal crystallization inhibitors in experimental nephrolithiasis. Bull Exp Biol Med. 2012;153(2):279-282.

7. Lulich JP, Osborne CA, Carvalho M, et al. Effects of a urolith prevention diet on urine compositions of glycosaminoglycans, Tamm-Horsfall glycoprotein, and nephrocalcin in cats with calcium oxalate urolithiasis. Am J Vet Res. 2012;73(3):447-51.

8. Malihi Z, Wu Z, Stewart AW. Hypercalcemia, hypercalciuria, and kidney stones in long-term studies of vitamin D supplementation: a systematic review and meta-analysis. Am J Clin Nutr. 2016;104(4):1039-1051. 